\title{
Donors' Quality of Life after Live Liver Transplantation and Social Support: A Correlation Study
}

\author{
Yefeng Lu1, Yan Yang2, Yan Wang1, Aiping Zhao², Longzhi Han', Xiaosong Chen1, \\ Jianjun Zhang1 ${ }^{1}$ Qiang Xia ${ }^{*}$ \\ ${ }^{1}$ Department of Hepatic Surgery, Renji Hospital, School of Medicine, Shanghai Jiao Tong University, Shanghai, \\ China \\ ${ }^{2}$ Nursing Department, Renji Hospital, School of Medicine, Shanghai Jiao Tong University, Shanghai, China \\ Email: xiaqiang@medmail.com.cn
}

Received 9 February 2014; revised 12 March 2014; accepted 21 March 2014

Copyright $@ 2014$ by authors and Scientific Research Publishing Inc.

This work is licensed under the Creative Commons Attribution International License (CC BY). http://creativecommons.org/licenses/by/4.0/

(c) () Op Open Access

\section{Abstract}

Objective: Donors' quality of life (QOL) and social support were investigated in this study. Method: The SF-36 scale and social support scale were used to survey the quality of life and social support of donors of live liver transplantation. Result: The PCS (Physical Correlated Score) is 84.78 \pm 13.21 , the MCS (Mental Correlated Score) is $80.71 \pm 14.65$, and the total score is $165.49 \pm$ 22.63. The results show the significant difference at GH (General Health) \& VT (Vitality) domain regarding the age, $\mathrm{P}<0.05$; while there's a significant difference at BP (Body Pain) domain regarding the sex, $P<0.05$. The social support score of male $\&$ female donors are $37.75 \pm 7.50$ and $44.00 \pm 4.30$, and the difference is significant, $P<0.05$. The MCS and the social support score are correlated, the correlation factor is $0.483, P<0.05$. Conclusion: There's no significant difference between the donors and the normal population. The age is the risk factor of QOL, and it should be paid more attention when we select the donor. Excellent social support relates to high quality of life.

\section{Keywords}

Live Liver Transplantation, Quality of Life, Social Support, Correlation Study

\footnotetext{
${ }^{*}$ Corresponding author.
} 


\section{Introduction}

The liver transplantation is the only effective therapy of many end-staged liver disease patients, but the lack of corpse liver impedes the development of liver transplantation, however, the live donor liver transplantation (LDLT) provides a new source of donated liver [1]. The LDLT is usually implemented between children and their parents or relatives [2]. However, the healthy body is the important requirement as the donor of LDLT, and they have to suffer the pain of operation or the danger of losing their lives [3], so we should pay attention to the donors' quality of life after operation. The LDLT donors' quality of life is a hot research topic overseas [4], and there's a study that indicates that the social support is in favor of improving the renal transplantation recipients' quality of life [5], therefore, it's equally important to care for this group's social support. In this study the donors of LDLT are regarded as the research object, and we aim at getting some knowledge about their quality of life, social support and their correlation by means of investigation, and hope to offer some references for the follow-up visit.

\section{Method}

\subsection{Research Object}

The research objects of this study are the LDLT donors who have received the operation in our department. Written informed consent was obtained from all subjects participating in the study.

\subsection{Research Design}

The cross-sectional investigative design was adopted in this study, and the instrument is the questionnaire. The questionnaires were delivered by email and mail. We sent 8 emails, and all were answered, while we sent 15 mails, and only 10 of them were answered.

\subsection{Research Measurements and Data Analysis}

The questionnaire was developed from the SF-36 Quality of Life Scale (Chinese Version) which was translated by Zhejiang University School of Medicine and the Social Support Scale. The SF-36 scale includes 8 domains, which are physical functioning (PF), role-physical (RP), body pain (BP), general health (GH), vitality (VT), social functioning (SF), role-emotional (RE), and mental health $(\mathrm{MH})$, and there're 10 items in the Social Support Scale.

The reliability of the questionnaire is 0.89 , and all data were entered into SPSS16.0 to analyze, and mean, standard deviation, t-test, relation were used.

\subsection{Data Transition}

1) The QOL Score: the method in the literature 6 was adopted, and more in Table 1 [6].

2) Transition Score $=(($ Original Score-Mini Score $) /$ Score Range $) \times 100$

Table 1. The calculation formula of SF-36 scale.

\begin{tabular}{|c|c|c|c|}
\hline Domain & Computation rules & Possible min \& max & Score range \\
\hline $\mathrm{PF}$ & $3 a+3 b+3 c+3 d+3 e+3 f+3 g+3 h+3 i+3 j$ & 10.30 & 20 \\
\hline $\mathrm{RP}$ & $4 a+4 b+4 c+4 d$ & 4.8 & 4 \\
\hline $\mathrm{BP}$ & $7+8$ & 2.11 & 9 \\
\hline $\mathrm{GH}$ & $1+11 a+11 b+11 c+11 d$ & 5.25 & 20 \\
\hline VT & $9 a+9 e+9 g+9 i$ & 4.24 & 20 \\
\hline $\mathrm{SF}$ & $6+10$ & 2.10 & 8 \\
\hline $\mathrm{RE}$ & $5 a+5 b+5 c$ & 3.6 & 3 \\
\hline MH & $9 b+9 c+9 d+9 f+9 h$ & 5.30 & 25 \\
\hline
\end{tabular}




\section{Results}

\subsection{Demographics}

There were 18 donors enrolled in this study, and the mean age is $35.11 \pm 8.49$ years old, the mean height is $165.06 \pm 10.01 \mathrm{~cm}$, the mean weight is $62.72 \pm 11.88 \mathrm{~kg}$, the mean post-operation time is $529.61 \pm 395.26$ days, and donors have $1.35 \pm 0.93$ children.

Donors were mostly female ( $\mathrm{n}=10,55.6 \%) ; 12$ (66.7\%) were graduate degrees, 2 (11.1\%) were high school, and the rest 4 (22.2\%) donors were illiteracy, elementary school, junior high school and college; 4 (22.2\%) were office workers, 3 (16.7\%) were farmers, 2 (11.1\%) were unemployed, 1 (5.6\%) was technician, $4(22.2 \%)$ were other profession; 14 (77.8\%) were married, 3 (16.7\%) were unmarried, 1 (5.6\%) was divorced; 13 (72.2\%) were normal economic status, 3 (16.7\%) were poor, 2 (11.1\%) were rich; 5 (27.8\%) donors reported relatively poor sexual life, 3 (16.7\%) were almost normal, 7 (38.9\%) were normal.

\subsection{Effect of Age}

The donors were divided into two groups according to the age, and they were young group (18 - $44 \mathrm{yr}$ ) and middle-aged group (45 - 64 yr). Two groups show significant difference on the domain of GH, VT, PCS and Total Score, and $\mathrm{P}<0.05$. The score of young group is higher than the middle-aged group. Complete information is shown in Table 2.

\subsection{Effect of Sex}

Two different groups show significant difference on the domain of BP, $\mathrm{P}<0.05$, and the score of male group is higher than the female group. Complete information is shown in Table 3.

\subsection{Effect of Different Group of Population}

We can conclude from Table 4 that the score of every domain of donors is not significantly different from other population, and the score of domain of RE is lower than the Hangzhou population and the Americans.

\subsection{The Effect of Sex and Age on Social Support}

Two sexual groups show significant difference on the total score of social support, $\mathrm{P}<0.05$, and the score of female group is higher than the male group. Besides, two age groups show significant difference on the domain of "Objective Support", $\mathrm{P}<0.05$, and the score of young group is higher than the middle-aged group. Complete information is shown in Table 5.

Table 2. The effect of age on the domain of SF-36 (M $\pm \mathrm{SD})$.

\begin{tabular}{ccccc}
\hline Domain & $18-44$ yrs & $45-64$ yrs & T statistics & P value \\
\hline PF & $96.79 \pm 3.17$ & $86.25 \pm 8.54$ & 2.421 & 0.088 \\
RP & $96.43 \pm 13.36$ & $50.00 \pm 57.74$ & 1.596 & 0.206 \\
BP & $92.86 \pm 9.35$ & $86.11 \pm 10.64$ & 1.238 & 0.233 \\
GH & $70.36 \pm 10.09$ & $56.25 \pm 11.09$ & 2.420 & $0.028^{*}$ \\
VT & $83.57 \pm 10.46$ & $70.00 \pm 13.54$ & 2.157 & $0.047^{*}$ \\
SF & $90.18 \pm 18.46$ & $75.00 \pm 42.08$ & 0.702 & 0.528 \\
RE & $78.57 \pm 28.06$ & $66.67 \pm 27.22$ & 0.752 & 0.463 \\
MH & $80.86 \pm 16.47$ & $75.00 \pm 21.01$ & 0.593 & 0.561 \\
PCS & $89.11 \pm 6.68$ & $69.65 \pm 20.07$ & 3.245 & $0.005^{*}$ \\
MCS & $83.29 \pm 12.61$ & $71.67 \pm 19.65$ & 1.444 & 0.168 \\
Total & $172.40 \pm 17.21$ & $141.32 \pm 24.83$ & 2.905 & $0.01^{*}$ \\
\hline
\end{tabular}

\footnotetext{
“*” indicating $\mathrm{P}<0.05$, the two different groups of age showed significant difference on that domain.
} 
Table 3. The Effect of Sex on the Domain of SF-36 $(\mathrm{M} \pm \mathrm{SD})$.

\begin{tabular}{ccccc}
\hline Domain & Male & Female & T statistics & P value \\
PF & $95.21 \pm 2.67$ & $94.13 \pm 8.43$ & 0.353 & 0.730 \\
RP & $96.33 \pm 14.32$ & $75.32 \pm 42.49$ & 1.861 & 0.096 \\
BP & $98.61 \pm 3.93$ & $85.56 \pm 9.15$ & 3.752 & $0.002^{*}$ \\
GH & $68.13 \pm 10.67$ & $66.50 \pm 12.93$ & 0.286 & 0.779 \\
VT & $77.50 \pm 11.95$ & $83.00 \pm 12.52$ & -0.945 & 0.359 \\
SF & $75.00 \pm 33.41$ & $96.25 \pm 8.44$ & 7.717 & 0.119 \\
RE & $79.17 \pm 30.54$ & $73.33 \pm 26.29$ & 0.436 & 0.669 \\
MH & $75.00 \pm 14.93$ & $83.20 \pm 18.55$ & -1.013 & 0.326 \\
PCS & $90.43 \pm 3.68$ & $80.26 \pm 16.37$ & 1.905 & 0.086 \\
MCS & $76.67 \pm 16.64$ & $83.95 \pm 12.80$ & -1.051 & 0.309 \\
Total & $167.10 \pm 20.10$ & $164.21 \pm 25.48$ & 0.262 & 0.797 \\
\hline
\end{tabular}

“*”, indicating $\mathrm{P}<0.05$, the two different groups of sex showed significant difference on that domain.

\section{Table 4. The effect of different population on the domain of SF-36 $(M \pm S D)$.}

\begin{tabular}{ccccccccc}
\hline Population & PF & RP & BP & GH & VT & SF & RE & MH \\
\hline $\begin{array}{c}\text { Donors of LDLT (18) } \\
\text { Hangzhou [5] (1688) }\end{array}$ & $94.4 \pm 6.4$ & $86.1 \pm 33.5$ & $91.4 \pm 9.8$ & $67.2 \pm 11.7$ & $80.6 \pm 12.2$ & $86.8 \pm 24.8$ & $75.9 \pm 27.5$ & $79.6 \pm 17.1$ \\
$\begin{array}{c}\text { Chinese Americans [6] } \\
\text { (156) }\end{array}$ & $79.4 \pm 23.4$ & $67.5 \pm 37.3$ & $62.3 \pm 21.9$ & $58.8 \pm 22.7$ & $59.0 \pm 20.3$ & $75.1 \pm 22.7$ & $61.2 \pm 43.7$ & $63.9 \pm 20.4$ \\
$\begin{array}{c}\text { Americans [7] } \\
\text { (2474) }\end{array}$ & $84.2 \pm 23.3$ & $81.0 \pm 34.0$ & $75.2 \pm 23.7$ & $72.0 \pm 20.3$ & $60.9 \pm 21.0$ & $83.3 \pm 22.7$ & $81.3 \pm 33.0$ & $74.7 \pm 18.0$
\end{tabular}

Table 5. The effect of sex \& age on the social support (M \pm SD).

\begin{tabular}{|c|c|c|c|c|}
\hline Items & Objective support score & Subjective support score & Support utilization & Total sore \\
\hline Male & $10.50 \pm 2.56$ & $19.38 \pm 4.87$ & $7.88 \pm 1.25$ & $37.75 \pm 7.50$ \\
\hline Female & $12.40 \pm 2.88$ & $22.60 \pm 3.54$ & $9.10 \pm 1.73$ & $44.00 \pm 4.30$ \\
\hline $\mathrm{T}$ statistics & -1.460 & -1.579 & -1.681 & -2.228 \\
\hline$P$ value & 0.164 & 0.134 & 0.112 & $0.041^{*}$ \\
\hline $18-44$ yrs & $12.07 \pm 2.97$ & $20.21 \pm 3.89$ & $8.50 \pm 1.16$ & $40.79 \pm 6.34$ \\
\hline $45-64$ yrs & $9.75 \pm 1.26$ & $24.25 \pm 4.99$ & $8.75 \pm 2.99$ & $42.75 \pm 8.14$ \\
\hline $\mathrm{T}$ statistics & 2.290 & -1.729 & -0.164 & -0.516 \\
\hline$P$ value & $0.04^{*}$ & 0.103 & 0.879 & 0.613 \\
\hline Total samples & $11.56 \pm 2.83$ & $21.11 \pm 4.35$ & $8.56 \pm 1.62$ & $41.22 \pm 6.57$ \\
\hline
\end{tabular}

“*” indicating $\mathrm{P}<0.05$.

\subsection{The Correlation between Quality of Life and Social Support}

The Mental Correlated Score (MCS) and the Total Score of Social Support is positive correlated, and the correlation coefficient is $0.483, \mathrm{P}<0.05$. The Total Score of SF-36 and the Total Score of Social Support is low-grade positive correlated, and the correlation coefficient is $0.111, \mathrm{P}>0.05$. Complete information is shown in Table 6.

\section{Discussions}

With the skill of LDLT being more advanced, it's operated more than before. Besides the prognosis, the donors' health after surgery also deserved the attention. The Quality of life (QOL) and Social Support are the common 
Table 6. The correlation between QOL and social support.

\begin{tabular}{cccc}
\hline & PCS & MCS & Overall life quality score \\
\hline Objective support score & 0.118 & 0.392 & 0.322 \\
P value & 0.642 & 0.108 & 0.192 \\
Subjective support score & -0.462 & 0.307 & -0.071 \\
P value & 0.054 & 0.216 & 0.779 \\
Support utilization & -0.368 & 0.451 & 0.077 \\
P value & 0.133 & 0.06 & 0.761 \\
Total score of social support & -0.346 & 0.483 & 0.111 \\
P value & 0.160 & $0.042^{*}$ & 0.661 \\
\hline
\end{tabular}

“*” indicating $\mathrm{P}<0.05$.

evaluation index, and the QOL focus on the healthy status [9]. The QOL scale in this study was cited from the SF-36 Quality of Life Scale (Chinese Version) which was translated by Zhejiang University School of Medicine [6]. There're SF-36, WHOQOL-BREF and WST119-1999 quality of life scale, and the SF-36 was chosen because it's a popular QOL scale in Europe, furthermore, most relative literature in China chose the SF-36. There's no literature about the QOL of live donors in China by now, so it's important to study the QOL \& Social Support of the live donors.

\subsection{Impact of Age on Donors' QOL}

The LDLT resolve the lack of corpse liver to a large extent, and the number of this kind of surgery rose rapidly during the past few years [10]. There were more than 13,000 cases of LDLT operated all over the world by 2008 [11], and this number in China is 1460 by Mar 2011 [12]. The LDLT brings the recipient new life, but it also brings the donors danger, even the death [13]. Then studying the donors' QOL is necessary. The results showed that the age is an important factor affecting the donors' QOL after operation. The age showed significant difference on the domain of GH, VT, MCS and total score, and P $<0.05$, and the score of Young group was higher than the one of Middle-aged group, and it was the same as the results of Togashi [10], while the PCS (Physical Correlated Score) \& MCS were higher, with the 53.8 \& 54.5 in the results of Togashi. The results of this study proved that it's important to think about the age when screening the donors. With the age increasing, it's more probably to have covert diseases, and most transplantation centers' upper limitation of donors' age is 65 years old [14]. And the limitation is 55 years old in Hong Kong [15].

\subsection{Impact of Sex on Donors' QOL}

The sex isn't the main element when assessing the LDLT [16]. The results showed the sex showing significant difference on the domain of BP, and $\mathrm{P}<0.05$. The score of male was higher than the one of female, which indicated that the male stand the pain more powerful than the female. However, it's probably that the male chose the higher score because of dignity and feudalism idea. Moreover, the MCS of male was lower than the one of female. The difference wasn't statistically significant, but it also deserves our attention, because it's the principle of liver donation to protect the donors from physical and psychological injury [17]. The donors should be offered more psychological support when we assessing their general status. There's research addressing [18] that mental symptoms were occurred at $14 \%$ female after operation, which highlighting the importance of psychological support before operation. If so, it will be good for psychological recovery, and it fits the ethical principles.

\subsection{QOL of Live Donors}

The QOL of live donors was compared with the one of Hangzhou people [6], American Chinese [7] and Americans [8]. The QOL of Hangzhou people was studied by Zhejiang University School of Medicine, and the results are reliable, which can represent the Chinese people to some extent. While the American Chinese can represent the Chinese abroad and the Americans can be a ruler. Considering the potential differences of different races, we 
can think there's no significant differences between the QOL of live donors and the one of other normal peoples, and some score of domain was higher than other normal people, and the reason can possibly be that the behavior of donating liver make them feel noble [19]. What's more important is that the donation can save their family members, and it makes them feel important, which is the same as the results of Feltrin [20].

\subsection{Social Support of Live Liver Donors}

The score of social support of the research objects was relatively high, and it showed significant difference on the factor of sex, $\mathrm{P}<0.05$. The score of female was higher than the one of male, which indicated that the female had gained more social support. The male should be given more emotional support, and they should be encouraged to obtain social support. Erim [17] reported that social support could protect the live donors from depression after operation, which prompts us that we should encourage the donors to pursue more social support when we give them discharge education. The more social support they have, the much healthier they will be. Moreover, the "objective support" showed significant difference on the factor of age, $\mathrm{P}<0.05$. The score of Young group was higher than the one of Middle-aged group, which indicated that the Young group had gained more social support. The potential cause may be that the life style and environment of Young group was more open, and the closed environment blocked the Middle-aged group gaining the objective support, and their family members should be encouraged to offer them more support and care.

\subsection{The Correlation between QOL and Social Support}

The results read that the MCS was positively correlated with the score of Social Support, and the correlation coefficient was $0.483, \mathrm{P}<0.05$. The QOL was also positively correlated with the score of Social Support, and the correlation coefficient was $0.111, \mathrm{P}>0.05$. The results indicated that enough social support will bring the donors high MCS, which was the same as the results of Yoshino [21]. It’s important to pay more attention to the social support status of donors after operation, because the social support will be good for the quality of life.

\section{Limitations}

The sample of this study is relatively small, and the popularization of results is limited. Further study should be operated in the future.

\section{Conclusion}

The QOL and social support of live liver donors were analyzed in this study, and we gained rough results. The results indicated that the QOL of donors were not significantly different from the normal people, and it proved that the LDLT is safe. Moreover, the social support gained from the donors was very optimistic, and enough social support is good for improving the QOL, which will call the healthcare workers' attention who work in the field of transplantation. And as a result, they will focus on the social support in the follow-up visit.

\section{Acknowledgements}

We would like to give extremely thanks to our colleagues for their help!

\section{References}

[1] Xia, Q. (2008) Several Question of Live Liver Transplantations. Journal of Surgery Concepts \& Practice, 13, $300-302$.

[2] Wang, Y. (2008) The Nursing Progress of Donors and Recipients of Live Liver Transplantations. Shanghai Nursing, 8, 57-61.

[3] Xia, Q. (2010) Break the Bottleneck of Liver Transplantation. Journal of Hepatobiliary Surgery, 18, 164-166.

[4] Verbesey, E.J., Simpson, A.M., Pomposelli, J.J., et al. (2005) Living Donor Adult Liver Transplantation: A Longitudinal Study of the Donor's Quality of Life. American Journal of Transplantation, 5, 2770-2777. http://dx.doi.org/10.1111/j.1600-6143.2005.01092.x

[5] Chen, W.C., Chen, C.H., Lee, P.C., et al. (2007) Quality of Life, Symptom Distress, and Social Support among Renal Transplant Recipients in Southern Taiwan: A Correlational Study. Journal of Nursing Research, 15, 319-328. http://dx.doi.org/10.1097/01.JNR.0000387628.33425.34 
[6] Wang, H.M., Li, L. and Shen, Y. (2001) The QOL Research of SF-36 (Chinese Version) Used to Hangzhou Urban Residents. Chinese Preventive Medicine, 35, 428-430.

[7] Ren, X.S., Amick, B., Zhou, L., et al. (1998) Translation and Psychometric Evaluation of a Chinese Version of the SF-36 Health Survey in the United States. Journal of Clinical Epidemiology, 51, 1129-1138. http://dx.doi.org/10.1016/S0895-4356(98)00104-8

[8] Ware, J.E., Snow, K.K., Kosinski, M., et al. (1993) SF-36 Health Survey Manual and Interpretation Guide. New England Medical Center, the Health Institute, Boston.

[9] Nicholas, D.B., Otley, A.R., Taylor, R., et al. (2010) Experiences and Barriers to Health-Related Quality of Life Following Liver Transplantation: A Qualitative Analysis of the Perspectives of Pediatric Patients and Their Parents. Health and Quality of Life Outcomes, 8, 1-8. http://dx.doi.org/10.1186/1477-7525-8-150

[10] Togashi, J., Sugawara, Y., Tamura, S., et al. (2010) Donor Quality of Life after Living Donor Liver Transplantation: A Prospective Study. Journal of Hepatobiliary Pancreat Science, 18, 263-267. http://dx.doi.org/10.1007/s00534-010-0340-y

[11] Zheng, S.S. and Wu, J. (2008) The Present Situation and the Development Tendency of LDLT in Our Country. Journal of Surgery Concepts \& Practice, 13, 285-287.

[12] China Liver Transplant Registry (2011) www.cltr.org

[13] Akabayashi, A., Slingsby, B.T. and Fujita, M. (2004) The First Donor Death after Living-Related Liver Transplantation in Japan. Transplantation, 77, 634. http://dx.doi.org/10.1097/01.TP.0000115342.98226.7C

[14] Soejima, Y., Shimada, M., Suehiro, T., et al. (2003) Use of Steatotic Graft in Living Donor Liver Transplantation. Transplantation, 76, 344-348. http://dx.doi.org/10.1097/01.TP.0000071205.52835.A4

[15] Fan, S.D. and Wang, H.B. (2008) The Assessment of Donors of Live Liver Transplantation. Chinese Journal of Practical Surgery, 28, 321-330.

[16] Xia, Q. (2009) The Progress of Living Donor Liver Transplantation. Chinese Journal of Gastroenterology, 14, 650651.

[17] Erim, Y., Bechmann, M., Kroencke, S., et al. (2008) Sense of Coherence and Social Support Predict Living Liver Donors' Emotional Stress Prior to Living-Donor Liver Transplantation. Clinical Transplant, 22, 273-280. http://dx.doi.org/10.1111/j.1399-0012.2007.00782.x

[18] Erim, Y., Beckmann, M., Gamazo, V.C., et al. (2006) Quality of Life and Psychiatric Complications after Adult Living Donor Liver Transplantation. Liver Transplantation, 12, 1782-1790. http://dx.doi.org/10.1002/lt.20907

[19] Lu, Y.F., Wang, Y. and Zhao, A.P. (2011) Research Progress of Nursing Ethics in Liver Transplantation. Journal of Shanghai Jiaotong University (Medical Science), 31, 723-726.

[20] Feltrin, A., Pegoraro, R., Rago, C., et al. (2008) Experience of Donation and Quality of Life in Living Kidney and Liver Donors. European Society for Organ Transplantation, 21, 466-472. http://dx.doi.org/10.1111/j.1432-2277.2007.00632.x

[21] Yoshino, M., Yoshino, H., Kusano, A., et al. (2007) The Influence of Living Donor Liver Transplantation on Families with or without Siblings. Pediatric Transplantation, 11, 624-627. http://dx.doi.org/10.1111/j.1399-3046.2007.00706.x 